\title{
Association of PPAR $\gamma 2$ (Pro12Ala) and neuropeptide Y (Leu7Pro) gene polymorphisms with obstructive sleep apnea in obese Asian Indians
}

\author{
Bharat Bhushan $^{\mathrm{a}}$, Randeep Guleria ${ }^{\mathrm{b}, *}$, Anoop Misra ${ }^{\mathrm{c}}$, Kalpana Luthra $^{\mathrm{d}}$ and Guresh Kumar ${ }^{\mathrm{e}}$ \\ ${ }^{a}$ Department of Surgery, Children's Memorial Hospital, Northwestern University, Chicago, USA \\ ${ }^{\mathrm{b}}$ Department of Medicine, All India Institute of Medical Sciences, New Delhi, India \\ ${ }^{\mathrm{c}}$ Diabetes and Metabolic Diseases, Fortis hospital, New Delhi, India \\ ${ }^{\mathrm{d}}$ Department of Biochemistry, All India Institute of Medical Sciences, New Delhi, India \\ e Department of Biostatistics, All India Institute of Medical Sciences, New Delhi, India
}

\begin{abstract}
Background: Obstructive sleep apnea (OSA) is prevalent in 7.5\% in urban Asian Indians. Peroxisome proliferator activated receptor gamma $2(P P A R \gamma 2)$ has been implicated in adipocyte differentiation. Neuropeptide $Y(N P Y)$ is also considered as a candidate gene for excess body fat accumulation. The association of PPAR 2 (Pro12Ala) and NPY (Leu7Pro) gene polymorphisms with OSA has not been studied in Asian Indians.

Objective: To study the distribution of PPAR 2 (Pro12Ala) and NPY (Leu7Pro) polymorphism in Asian Indians with and without OSA.

Methods and results: This study was carried out in 252 obese subjects [(body mass index (BMI $\left.>25 \mathrm{~kg} / \mathrm{m}^{2}\right)$ ]; 142 with OSA and 110 without OSA. Measurements included anthropometric and biochemical parameters (fasting blood glucose, lipid profile, various circumferences and skin-fold thicknesses). PPAR 2 (Pro12Ala) and NPY (Leu7Pro) gene polymorphisms were studied in all subjects. The frequency of the variant allele (Ala12) of PPAR 2 gene was significantly higher in subjects with OSA (14.4\%) when compared with subjects without OSA $\left(5.5 \% ; \chi^{2}=9.7 ; p=0.001\right)$. The distribution of the variant allele (Pro7) of NPY gene was comparable in subjects with OSA $(3.5 \%)$ and without OSA $\left(3.6 \% ; \chi^{2}=0.001, p=0.94\right)$.

Conclusion: This study reveals a significantly higher frequency of PPAR 2 (Ala12) allele in obese Asian Indians with OSA when compared to obese Asian Indians without OSA.
\end{abstract}

Keywords: Obstructive sleep apnea, PPAR gamma, neuropeptide Y, gene polymorphism, Asian Indians, obesity

\section{Introduction}

Obstructive sleep apnea (OSA) is a condition characterized by partial or complete upper airway obstruction during sleep. It leads to increased resistance to airflow and cessation of breathing during sleep. OSA

\footnotetext{
*Corresponding author: Randeep Guleria, Professor, Department of Medicine, All India Institute of Medical Sciences, Ansari Nagar, New Delhi - 110029, India. Tel.: +91 11 26593676; Fax: +91 11 26862663, +1 9111 26589732; E-mail: randeepguleria2002@ yahoo.com; Bharataiims@gmail.com.
}

affects about $4 \%$ to $9 \%$ of the adult population and children [40]. Prevalence of OSA is substantial (7.5\%) in urban Asian Indians residing in India [37]. OSA has been associated with increase in fatal and nonfatal cardiovascular events [9].

The primary risk factor for OSA is excessive weight gain. Other than male gender, obesity is the strongest risk factor for the development of OSA [38]. Various studies indicate that about $66 \%$ of patients with OSA are obese. Significant weight loss has been shown to have varying degrees of improvement in OSA [36]. A number of studies have demonstrated that obesity is 
genetically determined [41]. Studies in subjects with elevated apnea hypopnea index (AHI) provide insight to the possible genetic overlap between obesity and AHI. Several investigators have shown familial aggregation of AHI level and symptoms of OSA in adults obese and non-obese subjects [29].

In humans, there are three isoforms of the peroxisome proliferator-activated receptor gamma $(P P A R \gamma)$ gene; $\operatorname{PPAR} \gamma 1, \operatorname{PPAR} \gamma 2, \operatorname{PPAR} \gamma 3$. These are formed by alternative promoters and differential splicing [3]. Out of these three, PPAR $\gamma 2$ is expressed exclusively in adipose tissue [3]. PPAR $\gamma$ regulates adipocyte genes involved in adipogenesis and lipid metabolism. PPAR $\gamma$ activates adipocyte differentiation and mediates the expression of fat cell-specific genes [18]. Obesity and nutritional factors influence the expression of the PPAR $\gamma 2$ isoforms [11]. The most common variation involving $\mathrm{C}$ to A nucleotide substitution has been reported in exon2 of PPAR $\gamma 2$ gene. This single nucleotide substitution results in an amino acid change, Proline-to-Alanine at codon 12 of this gene $[6,15]$. In vitro experiments have demonstrated that this variation is associated with reduced transcriptional activity [12]. Association of PPAR 2 (Prol2Ala) polymorphism with body mass index (BMI) is conflicting. Few studies have shown that this polymorphism is associated with increased BMI [26] and others have even shown a negative or no association of this polymorphism with BMI [17,28]. Hsueh et al. (2001) reported that PPAR $\gamma 2$ (Prol2Ala) polymorphism accounted for $2-3 \%$ of the total variation of BMI in Mexican-American adults [19].

Neuropeptide Y (NPY) is a neurotransmitter that interacts with leptin in the regulation of sympathetic activity, body weight and energy balance. A recent study shows that NPY levels are increased in OSA independent of obesity [2]. Karvonen et al. (1998) have identified a Thymidine (1128) to Cytosine (1128) polymorphism (T1128C), which results in a substitution of Leu7 by Pro7 in the signal peptide part of pre-pro-NPY [24]. This polymorphism has also been found to be associated with increased birth weight [23]. Till date no study has been conducted on NPY (Leu7Pro) gene polymorphism in OSA subjects.

Previous studies on OSA conducted in Asian Indians have been limited to determining the prevalence of OSA and its relationship with road traffic accidents and public health awareness [16,37]. However, the status of PPAR 2 (Pro12Ala) and NPY (Leu7Pro) gene polymorphisms has not been investigated in Asian Indian subjects with OSA. We conducted a study in obese subjects with and without OSA, having comparable age, body mass index (BMI) and percentage body fat $(\% \mathrm{BF})$. In these two groups, we looked for the distribution of the polymorphic variants of PPAR $\gamma 2$ (Prol2Ala) and NPY (Leu7Pro).

\section{Methods}

\subsection{Subjects}

A total of 252 obese subjects; 142 newly diagnosed subjects with OSA (109 male, 33 females) and 110 subjects without OSA (71 males, 39 females) were recruited from the Medicine Out Patient Department of All India Institute of Medical Sciences, a tertiary care referral hospital. The subjects were North Indians residing in New Delhi or surrounding areas. Polysomnography (PSG) was performed in all subjects. On the basis of AHI, subjects were categorized as with and without OSA (see definitions). All subjects were free of any acute or apparent chronic inflammatory disorders, chronic obstructive pulmonary disease (COPD) and clinically apparent coronary heart disease (CHD). Subjects with other sleep disorders such as upper airway resistance syndrome (UARS), central sleep apnea syndrome (CSAS), periodic limbs movement (PLMs), or narcolepsy were excluded. Clinical evaluation for all subjects included thyroid profile and an electrocardiogram (ECG). The study was approved by the institutional ethics committee and written informed consent was obtained from all subjects before their participation in the study.

\subsection{Metabolic parameters}

Blood samples were obtained after an overnight fast for estimation of fasting blood glucose (FBG) and blood lipoproteins. Levels of FBG, total cholesterol (TC), serum triglycerides (TG) and high density lipoprotein-cholesterol (HDL-C) were estimated using commercial kits (Randox Laboratory, San Francisco, CA, USA) with a semi-automated analyzer (Micro Semi-Autoanalyser 2000, C.L. Micromed, Italy).

\subsection{Anthropometric measurements}

The anthropometric measurements were carried out by a physician according to the methods described earlier [13]. Briefly, waist circumference was measured midway between the highest point of the superior iliac crest and lowest point of the costal margin; hip circum- 
ference was measured at the maximum circumference of the buttocks. All measurements were taken in the standing position with feet placed together with subjects wearing only light clothes. Measurement of percentage body fat was carried out using leg-to-leg (two point contact) bioelectrical impedance method (Tanita TBF 300, TANITA Corp., Tokyo, Japan). For the estimation of bioelectrical impedance, subjects were evaluated after an overnight fast. They were instructed to avoid drinking fluids and void urine 1 hour prior to the measurements and just before the test. Gender and height details were manually entered into the system. The subject was instructed to stand on the apparatus so that both the feet were in firm contact with the surface of the apparatus and that hands were not touching any surface.

\subsection{Polysomnography (PSG)}

All subjects underwent overnight digital PSG (Medi palm; Braebon Medical Corp., Canada) and classified according to AHI. PSG channels included electrooculogram, electroencephalogram, electromyogram, an electrocardiogram and airflow (with an oro-nasal thermistor), chest and abdominal efforts, arterial oxyhemoglobin saturation by pulse oximeter. The recordings were analyzed with $60 \mathrm{sec}$ epoch, and sleep stages were scored according to the standard criteria of Rechtschaffen and Kales [33]. Obstructive apneas and hypopneas are typically distinguished from central events by the detection of respiratory efforts during the event.

\subsection{Definitions}

Obesity was defined as by criteria applicable to Asian Indians $\left(\mathrm{BMI}>25 \mathrm{~kg} / \mathrm{m}^{2}\right.$ ) [27]. Diagnosis of OSA was made on the basis of International classification of sleep disorders [34]. Apnea is defined as the cessation of airflow $\geqslant 10 \mathrm{~s}$ and hypopnea is defined as a recognizable, transient reduction of breathing $\geqslant 10 \mathrm{~s}$ associated with either an oxygen desaturation of $\geqslant 4 \%$ or an arousal [34]. The AHI was defined as the number of obstructive apneas and hypopneas per hour of sleep. Subjects with an AHI $<5$ /hour were assigned to not having OSA. Subjects with an AHI $\geqslant 5 /$ hour were considered to have OSA. Polysomnography was conducted in a single sleep laboratory and analysis was done by a single expert. The Epworth sleepiness scale (ESS) was used to check excessive daytime sleepiness [22]. A total score of less than 10 suggested that a person was not suffering from excessive sleepiness. ESS of 10 or more suggested the need for further evaluation to determine if an underlying sleep disorder was present [22].

\subsection{Isolation of DNA from blood}

Venous blood samples, $10 \mathrm{ml}$ each, were drawn into EDTA containing tubes for genomic DNA isolation. Genomic DNA was extracted from leucocytes after lysing the erythrocytes from the cell pellet. DNA was liberated by sodium dodecyl sulphate and proteinase $\mathrm{K}$ digestion overnight at $37^{\circ} \mathrm{C}$. Proteins were removed by addition of $5 \mathrm{M} \mathrm{NaCl}$, and the DNA was recovered by ethanol precipitation (Miller et al., 1983).

\subsection{PPAR $\gamma 2$ (Prol2Ala) gene polymorphism}

The polymorphic variants of PPAR 2 (Pro12Ala) and $N P Y$ (Leu7Pro) were determined by polymerase chain reaction-restriction fragment length polymorphisms (PCR-RFLP) [14]. The upstream primer sequence used for PPAR 2 (Prol2Ala) was 5'GCC AAT TCA AGC CCA GTC3' and downstream primer sequence was 5'GAT ATG TTT GCA GAC AGT GTA TCA GTG AAG GAA TCG CTT TCC G3'. The reaction was carried out in a final volume of $25 \mu \mathrm{l}$ containing $2.5 \mathrm{mM}$ of each dNTP (Bangalore Genei, India), $0.1 \mu \mathrm{mol}$ of each primer, $1.25 \mathrm{U}$ of Taq DNA polymerase (Bangalore Genei, India). DNA was amplified during initial denaturation at $94^{\circ} \mathrm{C}$ for 1 minute, followed by 34 cycles with $1 \mathrm{~min}$ denaturation at $94^{\circ} \mathrm{C}$, 1 minute annealing at $60^{\circ} \mathrm{C}$ and 1 minute extension at $72^{\circ} \mathrm{C}$. At the end of 34 cycles, a final step of extension at $72^{\circ} \mathrm{C}$ for 10 minute was performed. The PCR product was digested with $0.5 \mu \mathrm{l}$ of $B s t U 1$ restriction enzyme (New England Biolabs, UK). RFLP analysis yielded three bands, a 270bp fragment corresponding to the wild type allele and a set of $243 \mathrm{bp}$ and $23 \mathrm{bp}$ corresponding to variant allele.

\subsection{Neuropeptide Y (Leu7Pro) gene polymorphism}

For NPY (Leu7Pro) gene polymorphism, the upstream primer sequence was 5'CCC GTC CGT TGA GCC TTC TG3' and downstream primer sequence was 5'CGG TCC CGC GGT CCC3'. The detailed method is mentioned elsewhere [24]. Briefly, DNA was amplified during initial denaturation at $94^{\circ} \mathrm{C}$ for $5 \mathrm{~min}$, followed by 34 cycles with $1 \mathrm{~min}$ denaturation at $94^{\circ} \mathrm{C}$, 1 minute annealing at $62^{\circ} \mathrm{C}$ and 1 minute extension at $72^{\circ} \mathrm{C}$. A final step of extension was carried out at $72^{\circ} \mathrm{C}$ for 1 minute. The PCR product was digested with $0.5 \mu \mathrm{l}$ of BsiE1 restriction enzyme (New England Biolabs). The digested products were resolved by electrophoresis on a $2.5 \%$ agarose gel and visualized by ethidium bromide staining. 
Table 1

Characteristics of subjects with and without OSA

\begin{tabular}{lccl}
\hline Variables & $\begin{array}{c}\text { Subjects with OSA } \\
(n=142)\end{array}$ & $\begin{array}{c}\text { Subjects without } \\
\text { OSA }(n=110)\end{array}$ & p value \\
\hline BMI $\left(\mathrm{Kg} / \mathrm{m}^{2}\right)$ & $31.7 \pm 3.5$ & $30.8 \pm 3.9$ & 0.08 \\
Age $(\mathrm{y})$ & $46.1 \pm 10.8$ & $43.7 \pm 9.7$ & 0.07 \\
$\%$ BF & $37.4 \pm 10.3$ & $36.2 \pm 9.2$ & 0.35 \\
Blood pressure $(\mathbf{m m H g})$ & & \\
SBP & $135.3 \pm 17.1$ & $132.4 \pm 17.8$ & 0.23 \\
DBP & $89.8 \pm 11.4$ & $85.3 \pm 10.5$ & 0.004 \\
Circumferences $(\mathbf{c m s})$ & & \\
WC & $104.8 \pm 6.7$ & $130.1 \pm 9.0$ & 0.11 \\
NC & $39.2 \pm 4.5$ & $38.0 \pm 3.3$ & 0.02 \\
HC & $106.6 \pm 12.4$ & $100.2 \pm 7.4$ & 0.001 \\
CC & $38.6 \pm 3.6$ & $35.6 \pm 3.0$ & 0.001 \\
Blood glucose during OGTT (mg/dl) & & \\
FBG & $122.2 \pm 75.8$ & $106.4 \pm 24.8$ & 0.03 \\
2h-BG & $156.4 \pm 42.6$ & $141.0 \pm 42.7$ & 0.01 \\
Lipid profile (mg/dl) & & \\
TC & $196.2 \pm 46.1$ & $186.8 \pm 35.2$ & 0.09 \\
TG & $170.6 \pm 88.5$ & $168.6 \pm 61.6$ & 0.85 \\
HDL-C & $44.1 \pm 7.4$ & $44.3 \pm 5.5$ & 0.84 \\
\hline
\end{tabular}

Data have been described as mean+SD: BMI, Body mass index: \%BF, percentage body fat: SBP, Systolic blood pressure: DBP, Diastolic blood pressure: WC, Waist circumference: NC, Neck circumference: HC, Hip circumference: CC, Calf circumference: OGTT, Oral glucose tolerance test: FBG, Fasting blood glucose: 2h-BG, 2 hours blood glucose: TC, Total Cholesterol: TG, Triglycerides: HDL-C, High density lipoprotein-Cholesterol.

\subsection{Statistical methods}

Data were managed using an excel spreadsheet (Microsoft Corp., Washington, USA). Mean and standard deviation (S.D) were used as summary measures. Comparison between subjects with and without OSA was done by parametric ' $t$ ' test for continuous variables. The categorical variables were analyzed by using $\mathrm{Chi}^{2} /$ Fisher exact test, wherever applicable. Multiple logistic regression analysis was done to see possible risk factors for OSA. The Hardy-Weinberg equilibrium was tested by using $\left(\mathrm{p}^{2}+2 \mathrm{pq}+\mathrm{q}^{2}=1\right)$ formula and $\mathrm{chi}^{2}$ analysis. In a preliminary study conducted by us, proportion of Pro12Ala genotype was $24 \%$ in OSA group and $10 \%$ in Non OSA group. With alpha $=5 \%$ and power $80 \%, 252$ subjects were found to be appropriate for this study. STATA-9 statistical software was used for data analysis and $p<0.05$ was considered as statistically significant.

\section{Results}

Table 1 shows the characteristics of subjects with and without OSA. There was no significant difference in the mean age, Body mass index (BMI), \% body fat (\%BF) and waist circumference (WC) between subjects with
Table 2

Epworth sleepiness scale and polysomnography variables

\begin{tabular}{lccl}
\hline Variables & $\begin{array}{c}\text { Subjects with } \\
\text { OSA }(n=142)\end{array}$ & $\begin{array}{c}\text { Subjects without } \\
\text { OSA }(n=110)\end{array}$ & p value \\
\hline TST & $6.5 \pm 0.94$ & $6.4 \pm 0.81$ & 0.60 \\
Sleep Efficiency & $79.2 \pm 6.2$ & $87.4 \pm 6.7$ & 0.001 \\
Stage 1 sleep & $29.1 \pm 10.5$ & $15.2 \pm 9.9$ & 0.001 \\
Stage 2 sleep & $44.1 \pm 7.8$ & $55.0 \pm 6.7$ & 0.001 \\
Delta sleep & $7.4 \pm 3.0$ & $10.1 \pm 4.1$ & 0.001 \\
REM sleep & $11.7 \pm 4.2$ & $17.8 \pm 4.6$ & 0.001 \\
Mean SpO & $85.5 \pm 9.7$ & $96.4 \pm 2.4$ & 0.001 \\
Minimum $\mathrm{SpO}_{2}$ & $75.4 \pm 12.7$ & $94.2 \pm 4.5$ & 0.001 \\
ESS & $13.9 \pm 4.8$ & $7.9 \pm 3.5$ & 0.001 \\
\hline
\end{tabular}

TST, Total sleep time: REM, Rapid eye movement: ESS, Epworth sleepiness scale.

and without OSA. Diastolic blood pressure (DBP) was significantly higher in subjects with OSA but no difference was observed in systolic blood pressure (SBP) between these two groups. Neck circumference (NC), hip circumference $(\mathrm{HC})$ and calf circumference $(\mathrm{CC})$ were significantly higher in subjects with OSA as compared to the subjects without OSA. Fasting blood glucose (FBG) levels as well as blood glucose during 2hour (2h-BG) after 75 grams oral glucose load was significantly higher in subjects with OSA when compared with subjects without OSA. TC, TG and HDL-C levels were comparable in both groups. Table 2 shows the ESS and polysomnography profile of subjects with and without OSA. 
Table 3

Genotype and allele frequency of PPAR $\gamma 2$ and NPY gene

\begin{tabular}{lcccc}
\hline & $\begin{array}{c}\text { Subjects with } \\
\text { OSA: n (\%) }\end{array}$ & $\begin{array}{c}\text { Subjects without } \\
\text { OSA: } \mathrm{n}(\%)\end{array}$ & $\chi^{2}$ & $p$ value \\
\hline PPAR $\boldsymbol{2}$ 2 & & & & \\
Pro12Pro & $104(73.2)$ & $98(89.1)$ & 10.5 & 0.005 \\
Pro12Ala & $35(24.6)$ & $12(10.9)$ & & \\
Ala12Ala & $3(2.1)$ & $0(0)$ & & \\
Pro12 & $243(85.5)$ & $208(94.5)$ & 9.7 & 0.001 \\
Ala12 & $41(14.4)$ & $12(5.5)$ & & \\
NPY & & & & \\
Leu7Leu & $132(92.9)$ & $102(92.7)$ & 0.001 & 0.94 \\
Leu7Pro & $10(7.1)$ & $8(7.2)$ & & \\
Leu7 & $274(96.5)$ & $212(96.3)$ & 0.001 & 0.94 \\
Pro7 & $10(3.5)$ & $8(3.6)$ & & \\
\hline
\end{tabular}

The frequency of PPAR $\gamma 2$ (Ala12) allele was significantly higher in subjects with OSA $(14.4 \%)$ when compared with subjects without OSA $\left(5.5 \% ; \chi^{2}=9.7\right.$; $p=0.001$; Table 3). Allelic distribution of PPAR 2 (Pro12Ala) in the subjects without OSA was in HardyWeinberg equilibrium. The distribution of the variant 'Pro7' allele in NPY gene was similar in subjects with OSA $(3.5 \%)$ when compared with subjects without OSA $\left(3.6 \% ; \chi^{2}=0.001, p=0.94\right.$; Table 3$)$.

When OSA subjects having PPAR $\gamma 2$ (Ala12) allele were compared with subjects without OSA having PPAR 2 (Ala12) allele, SBP and DBP, HC and CC were significantly higher in subjects with OSA having PPAR $\gamma 2$ (Ala12) allele. Other variables (age, BMI, $\% \mathrm{BF}, \mathrm{WC}$ and $\mathrm{NC}$, fasting as well as $2 \mathrm{~h}-\mathrm{BG}$ and lipid levels) were comparable in both of these groups (Table 4).

When OSA subjects with PPAR $\gamma 2$ (Ala12) allele were compared with OSA subjects with PPAR $\gamma 2$ (Pro12) allele, there was no significant difference in age, BMI and \%BF. AHI was significantly higher in subjects with OSA having PPAR 2 (Ala12) allele [median (range); 33.5 (7-121)/h] when compared with subjects with OSA having PPAR $\gamma 2$ (Prol2) allele [17.9(5$88) / \mathrm{h}, p=0.002]$. TG levels were significantly higher in subjects with OSA having PPAR $\gamma 2$ (Ala12) allele $[($ mean $\pm \mathrm{SD}) ;(198.2 \pm 79.5) \mathrm{mg} / \mathrm{dl}]$ when compared with subjects with OSA having PPAR 2 (Prol2) allele $[(160.7 \pm 89.9) \mathrm{mg} / \mathrm{dl}, p=0.03]$. All anthropometry measurements, blood pressure, fasting as well as 2h-BG and lipid levels were comparable in subjects with OSA having PPAR $\gamma 2$ (Ala12) allele, when compared to subjects with OSA having PPAR 2 (Pro12) allele. Logistic regression analysis showed that AHI [OR (95\%CI); 1.01(1.00-1.04), $p=0.007]$ and rapid eye moment (REM) sleep [0.88(0.79-0.98), $p=0.02]$ were independent predictor for PPAR $\gamma 2$ (Ala12) al- lele in subjects with OSA. Subjects with OSA having PPAR $\gamma$ (Pro12Ala) genotype were having significantly higher serum TG levels when compared with subjects having PPAR $\gamma 2$ (Prol2Pro) genotype (198.2 \pm 79.5 vs. $160.8 \pm 89.9 ; p=0.04)$.

All parameters were comparable between OSA subjects carrying either the NPY (Pro7) allele or NPY (Leu7) allele. CC was significantly higher in OSA subjects with having NPY $($ Pro7) allele $[(39.5+3.0) \mathrm{cm}]$, when compared with subjects without OSA having NPY (Pro7) allele $[(35.6+0.5) \mathrm{cm}, p=0.008]$. NC (39.6 \pm 3.6 vs. $34.8 \pm 9.4 ; p=0.001)$ and $\mathrm{HC}(107.8 \pm 9.4$ vs. $94.1 \pm 28.3 ; p=0.001)$ was significantly higher in subjects with OSA having NPY (Leu7Leu) genotype when compared with NPY (Leu7Pro) genotype.

\section{Discussion}

This study is the first attempt to determine the PPAR 2 (Pro12Ala) and NPY (Leu7Pro) gene polymorphisms in OSA subjects. We found that the frequency of PPAR 2 (Ala12) allele was three times higher in subjects with OSA when compared with subjects without OSA. Frequency of NPY (Pro7) allele was comparable in subjects with and without OSA. These findings suggest a possible role of PPAR $\gamma 2$ (Ala12) allele in OSA.

In Asian Indians, previous studies on PPAR 2 (Pro12Ala) gene polymorphism have been conducted in diabetes [31] and colorectal cancer [21]. Radha et al. (2006) have shown that PPAR 2 (Ala12) allele is protective against type 2 diabetes mellitus (T2DM) in Caucasians but not in south Asians [32]. Jiang et al. (2005) has shown that C161T and not Pro12Ala polymorphism of the PPAR $\gamma$ gene is related to the risk of colorectal cancer.

Peroxisome proliferator-activated receptors (PPARs) are members of the nuclear hormone receptor superfamily that play a pivotal role in regulating inflammatory gene expression [10]. PPAR also plays an important role in the transcriptional regulation of lipid utilization and storage in several organs [1]. PPAR $\gamma$ ligands are used for therapy of T2DM and hold the promise for treatment of inflammation [7].

PPAR 2 (Pro12Ala) polymorphism has been studied in obese subjects in different populations worldwide (16-20). The role of this polymorphism is conflicting in obesity. Some reports show positive association whereas other show negative or no association with BMI $[17,28]$. Previous reports suggest the 
Table 4

Comparison of variables in subjects with and without OSA having $P P A R \gamma 2$ (Ala) allele

\begin{tabular}{|c|c|c|c|}
\hline Variables & $\begin{array}{l}\text { Subjects with OSA } \\
\text { having Ala12 allele } \\
\quad(n=38)\end{array}$ & $\begin{array}{l}\text { Subjects without OSA } \\
\text { having Ala12 allele } \\
(n=12)\end{array}$ & $p$ value \\
\hline BMI $\left(\mathrm{kg} / \mathrm{m}^{2}\right)$ & $31.0 \pm 3.6$ & $30.0 \pm 2.2$ & 0.24 \\
\hline Age $(y)$ & $44.3 \pm 11.1$ & $39.7 \pm 7.6$ & 0.12 \\
\hline$\% \mathrm{BF}$ & $35.7 \pm 8.0$ & $39.2 \pm 11.5$ & 0.36 \\
\hline \multicolumn{4}{|c|}{ Blood pressure (mmHg) } \\
\hline SBP & $140.0 \pm 19.6$ & $125.8 \pm 11.6$ & 0.008 \\
\hline DBP & $93.0 \pm 12.5$ & $83.5 \pm 6.1$ & 0.003 \\
\hline \multicolumn{4}{|c|}{ Circumferences (cms) } \\
\hline WC & $105.5 \pm 7.3$ & $103.4 \pm 3.7$ & 0.19 \\
\hline $\mathrm{NC}$ & $39.3 \pm 3.8$ & $39.5 \pm 3.6$ & 0.93 \\
\hline $\mathrm{HC}$ & $107.4 \pm 9.6$ & $100.3 \pm 6.0$ & 0.005 \\
\hline $\mathrm{CC}$ & $38.2 \pm 3.1$ & $35.6 \pm 2.5$ & 0.01 \\
\hline \multicolumn{4}{|c|}{ Blood glucose during OGTT (mg/dl) } \\
\hline FBG & $109.7 \pm 21.2$ & $100.7 \pm 10.2$ & 0.06 \\
\hline 2h-BG & $151.2 \pm 39.4$ & $138.3 \pm 35.7$ & 0.30 \\
\hline \multicolumn{4}{|c|}{ Lipid profile (mg/dl) } \\
\hline $\mathrm{TC}$ & $193.5 \pm 42.8$ & $20.4 .3 \pm 40.5$ & 0.47 \\
\hline TG & $198.1 \pm 79.5$ & $164.7 \pm 79.4$ & 0.24 \\
\hline HDL-C & $45.9 \pm 5.0$ & $44.1 \pm 4.6$ & 0.31 \\
\hline \multicolumn{4}{|c|}{$\begin{array}{l}\text { Data have been represented as mean } \pm \text { SD: BMI, Body mass index: } \% \text { BF, } \\
\text { percentage body fat: SBP, Systolic blood; Pressure: DBP, Diastolic blood } \\
\text { pressure: WC, Waist circumference: NC, Neck circumference: HC, Hip } \\
\text { circumference: CC, Calf circumference: OGTT, Oral glucose tolerance } \\
\text { test: FBG, Fasting blood glucose: } 2 \mathrm{~h}-\mathrm{BG}, 2 \text { hours blood glucose: TC, } \\
\text { Total Cholesterol: TG, Triglycerides: HDL-C, High density lipoprotein- } \\
\text { Cholesterol. }\end{array}$} \\
\hline
\end{tabular}

$P P A R \gamma 2$ gene is involved in adipogenesis and presence of PPAR 2 (Pro12Ala) polymorphism decreases the expression of PPAR $\gamma$ gene [15]. This may be associated with lower BMI. In our study, the effect of obesity was ruled out by recruitment of subjects with comparable age, BMI and \%BF. Furthermore, the mean AHI was significantly higher and other variables remained comparable in subjects with OSA having PPAR $\gamma 2$ (Ala12) allele, when compared to subjects with OSA having PPAR 2 (Pro12) allele.

PPAR 2 (Ala12) allele has also been found to be associated with increased inflammation [39]. In our previous studies, we have reported increased $\mathrm{C}$ reactive protein and tumor necrosis factor alpha levels in OSA [4,5]. PPAR $\gamma 2$ (Ala12) allele has also been found to be associated with decreased carotid artery intima-media thickness [20]. The exact mechanism, how PPAR $\gamma$ affects OSA and whether PPAR $\gamma 2$ gene has some association in pathophysiology of OSA, needs to be investigated.

NPY has been considered as a thrifty gene due to its role in weight regulation and energy balance [35]. Previously, two reports have been published on serum NPY levels in subjects with OSA [2,8]. One study showed increased levels of NPY in OSA subjects in Spanish population [2] while the other study failed to show an increase in serum NPY protein levels in OSA subjects in Swedish population [8]. The NPY (Leu7Pro) polymorphism has not been reported in above studies. In our study, the distribution of NPY (Pro7) allele was similar between subjects with and without OSA. Our findings suggest that NPY (Leu7Pro) polymorphism may not have a role to play in the pathophysiology of OSA. This needs to be substantiated by studying more number of subjects.

The strength of our study is that the cases were carefully selected to avoid effect of any apparent acute or chronic inflammatory disease or infections. Age, BMI and $\% \mathrm{BF}$ were matched carefully to see the independent effect of OSA. Pritchard and Roserberg [30] argued for the use of unlinked genetic markers to detect population stratification in association studies. Appropriate numbers of genetic markers were not looked in these subjects. Due to this, we were not able to check the effect of population stratification as suggested by Pritchard et al. [30]. Numerous studies have also looked at whether stratification really is a major issue in such studies and found the error rates to be extremely small [25]. 
Our study suggests increased frequency of Ala12 allele of PPAR 2 gene subjects with OSA. To conclude, $P P A R \gamma 2$ gene should be investigated as a candidate gene for OSA in a large population and also in different ethnic groups. We did not find any association of $N P Y$ gene polymorphism with OSA.

\section{Acknowledgments}

We acknowledge the help of staff of SRB Centre of Clinical Pharmacology, Department of Medicine, All India Institute of Medical Sciences, New Delhi including Ramesh Giri and Gian Chand for helping in performing various investigations. Dhanpat, Shyamsunder and Parmaal maan are thankful for their help to maintain sleep laboratory as well as in recruitment of subjects from out patient department. Cooperation of subjects who took part in the study and the help extended by their attendants are greatly appreciated.

\section{Finance disclosure}

None.

\section{References}

[1] E. Aasum, A.M. Khalid, O.A. Gudbrandsen, O.J. How, R.K. Berge and T.S. Larsen, Fenofibrate modulates cardiac and hepatic metabolism and increases ischemic tolerance in dietinduced obese mice, J Mol Cell Cardiol (2007).

[2] A. Barcelo, F. Barbe, E. Llompart, M. de la Pena, J. DuranCantolla, A. Ladaria et al., Neuropeptide Y and leptin in patients with obstructive sleep apnea syndrome: role of obesity, Am J Respir Crit Care Med 171 (2005), 183-187.

[3] J.P. Berger, T.E. Akiyama and P.T. Meinke, PPARs: therapeutic targets for metabolic disease, Trends Pharmacol Sci $\mathbf{2 6}$ (2005), 244-251.

[4] R. Guleria, B. Bhushan, A. Misra, N.K. Vikram, R.M. Pandey and K. Luthra, Relationship of subclinical inflammation with obstructive sleep apnea in obese Asian Indians. CHEST (2006) 94S.

[5] R. Guleria and B. Bhushan, TNF alpha level is directly associated with obstructive sleep apnoea in obese Asian Indians, Chest 132 (2007), 645Sa.

[6] M. Bluher, G. Lubben and R. Paschke, Analysis of the relationship between the Pro12Ala variant in the PPAR-gamma2 gene and the response rate to therapy with pioglitazone in patients with type 2 diabetes, Diabetes Care 26 (2003), 825-831.

[7] E. Burgermeister and R. Seger, MAPK kinases as nucleocytoplasmic shuttles for PPARgamma, Cell Cycle 6 (2007), 1539-1548.

[8] J.T. Carlson, J. Hedner, M. Elam, H. Ejnell, J. Sellgren and B.G. Wallin, Augmented resting sympathetic activity in awake patients with obstructive sleep apnea, Chest 103 (1993), 17631768.
[9] A. Cassar, T.I. Morgenthaler, R.J. Lennon, C.S. Rihal and A. Lerman, Treatment of obstructive sleep apnea is associated with decreased cardiac death after percutaneous coronary intervention, J Am Coll Cardiol 50 (2007), 1310-1314.

[10] S.Y. Choi, J.H. Chung, D.H. Kim, S.W. Chung, J.Y. Kim, B.P. Yu et al., Peroxisome proliferator-activated receptor gamma agonist action of 3-methyl-1,2-cyclopentanedione, Biochim Biophys Acta (2007).

[11] C.W. Danawati, M. Nagata, H. Moriyama, K. Hara, H. Yasuda, M. Nakayama et al., A possible association of Pro12Ala polymorphism in peroxisome proliferator-activated receptor gamma2 gene with obesity in native Javanese in Indonesia, Diabetes Metab Res Rev 21 (2005), 465-469.

[12] S.S. Deeb, L. Fajas, M. Nemoto, J. Pihlajamaki, L. Mykkanen, J. Kuusisto et al., A Pro12Ala substitution in PPARgamma2 associated with decreased receptor activity, lower body mass index and improved insulin sensitivity, Nat Genet 20 (1998), 284-287.

[13] V. Dudeja, A. Misra, R.M. Pandey, G. Devina, G. Kumar and N.K. Vikram, BMI does not accurately predict overweight in Asian Indians in northern India, Br J Nutr 86 (2001), 105-112.

[14] P.W. Franks, J. Luan, P.O. Browne, A.H. Harding, S. O'Rahilly, V.K. Chatterjee et al., Does peroxisome proliferator-activated receptor gamma genotype (Pro12ala) modify the association of physical activity and dietary fat with fasting insulin level? Metabolism 53 (2004), 11-16.

[15] L. Frederiksen, K. Brodbaek, M. Fenger, T. Jorgensen, K. Borch-Johnsen, S. Madsbad et al., Comment: studies of the Pro12Ala polymorphism of the PPAR-gamma gene in the Danish MONICA cohort: homozygosity of the Ala allele confers a decreased risk of the insulin resistance syndrome, J Clin Endocrinol Metab 87 (2002), 3989-3992.

[16] R. Guleria, Sleep apnoea and road traffic accidents, Natl Med J India 13 (2000), 22-23.

[17] A. Hamann, H. Munzberg, P. Buttron, B. Busing, A. Hinney, H. Mayer et al., Missense variants in the human peroxisome proliferator-activated receptor-gamma2 gene in lean and obese subjects, Eur J Endocrinol 141 (1999), 90-92.

[18] A. Hammarstedt, C.X. Andersson, V. Rotter Sopasakis and U. Smith, The effect of PPARgamma ligands on the adipose tissue in insulin resistance, Prostaglandins Leukot Essent Fatty Acids 73 (2005), 65-75.

[19] W.C. Hsueh, S.A. Cole, A.R. Shuldiner, B.A. Beamer, J. Blangero, J.E. Hixson et al., Interactions between variants in the beta3-adrenergic receptor and peroxisome proliferatoractivated receptor-gamma2 genes and obesity, Diabetes Care 24 (2001), 672-677.

[20] E. Iwata, I. Yamamoto, T. Motomura, S. Tsubakimori, S. Nohnen, M. Ohmoto et al., The association of Pro12Ala polymorphism in PPARgamma2 with lower carotid artery IMT in Japanese, Diabetes Res Clin Pract 62 (2003), 55-59.

[21] J. Jiang, V. Gajalakshmi, J. Wang, K. Kuriki, S. Suzuki, S. Nakamura et al., Influence of the C161T but not Pro12Ala polymorphism in the peroxisome proliferator-activated receptor-gamma on colorectal cancer in an Indian population, Cancer Sci 96 (2005), 507-512.

[22] M.W. Johns, A new method for measuring daytime sleepiness: the Epworth sleepiness scale, Sleep 14 (1991), 540-545.

[23] M.K. Karvonen, M. Koulu, U. Pesonen, M.I. Uusitupa, A. Tammi, J. Viikari et al., Leucine 7 to proline 7 polymorphism in the preproneuropeptide $\mathrm{Y}$ is associated with birth weight and serum triglyceride concentration in preschool aged children, $J$ Clin Endocrinol Metab 85 (2000), 1455-1460. 
[24] M.K. Karvonen, U. Pesonen, M. Koulu, L. Niskanen, M. Laakso, A. Rissanen et al., Association of a leucine(7)-to-proline(7) polymorphism in the signal peptide of neuropeptide $\mathrm{Y}$ with high serum cholesterol and LDL cholesterol levels, Nat Med 4 (1998), 1434-1437.

[25] M. Khlat, M.H. Cazes, E. Genin and M. Guiguet, Robustness of case-control studies of genetic factors to population stratification: magnitude of bias and type I error, Cancer Epidemiol Biomarkers Prev 13 (2004), 1660-1664.

[26] K.S. Kim, S.M. Choi, S.U. Shin, H.S. Yang and Y. Yoon, Effects of peroxisome proliferator-activated receptor-gamma 2 Pro12Ala polymorphism on body fat distribution in female Korean subjects, Metabolism 53 (2004), 1538-1543.

[27] A. Misra, P. Chowbey, B.M. Makkar, N.K. Vikram, J.S. Wasir, D. Chadha et al., Consensus statement for diagnosis of obesity, abdominal obesity and the metabolic syndrome for Asian Indians and recommendations for physical activity, medical and surgical management, J Assoc Physicians India 57 (2009), 163-170.

[28] M.B. Mohamed, N. Mtiraoui, I. Ezzidi, M. Chaieb, T. Mahjoub and W.Y. Almawi, Association of the peroxisome proliferatoractivated receptor-gamma2 Pro12Ala but not the C1431T gene variants with lower body mass index in Type 2 diabetes, $J$ Endocrinol Invest 30 (2007), 937-943.

[29] L.J. Palmer, S.G. Buxbaum, E. Larkin, S.R. Patel, R.C. Elston, P.V. Tishler et al., A whole-genome scan for obstructive sleep apnea and obesity, Am J Hum Genet 72 (2003), 340-350.

[30] J.K. Pritchard and N.A. Rosenberg, Use of unlinked genetic markers to detect population stratification in association studies, Am J Hum Genet 65 (1999), 220-228.

[31] V. Radha and V. Mohan, Genetic predisposition to type 2 diabetes among Asian Indians, Indian J Med Res 125 (2007), 259-274.

[32] V. Radha, K.S. Vimaleswaran, H.N. Babu, N. Abate, M. Chandalia, P. Satija et al., Role of genetic polymorphism peroxisome proliferator-activated receptor-gamma2 Pro12Ala on ethnic susceptibility to diabetes in South-Asian and Cau- casian subjects: Evidence for heterogeneity, Diabetes Care 29 (2006), 1046-1051.

[33] A. Kales and A. Rechtschaffen, A manula of standardized terminology, techniques and scoring system for sleep stages of human subjects., in, Brain Information Services/Brain Research Institute, University of California, Los Angeles, 1968.

[34] A. Kales and A. Rechtschaffen, The international classification of sleep disorders. Diagnostic and coding manual, in, 2nd ed, 1997.

[35] E. Rohner-Jeanrenaud and B. Jeanrenaud, Central nervous system and body weight regulation, Ann Endocrinol (Paris) 58 (1997), 137-142.

[36] P.L. Smith, A.R. Gold, D.A. Meyers, E.F. Haponik and E.R. Bleecker, Weight loss in mildly to moderately obese patients with obstructive sleep apnea, Ann Intern Med 103 (1985), 850-855.

[37] Z.F. Udwadia, A.V. Doshi, S.G. Lonkar and C.I. Singh, Prevalence of sleep-disordered breathing and sleep apnea in middleaged urban Indian men, Am J Respir Crit Care Med 169 (2004), 168-173.

[38] A.N. Vgontzas, D.A. Papanicolaou, E.O. Bixler, K. Hopper, A. Lotsikas, H.M. Lin et al., Sleep apnea and daytime sleepiness and fatigue: relation to visceral obesity, insulin resistance, and hypercytokinemia, J Clin Endocrinol Metab 85 (2000), 1151-1158.

[39] J. Westerbacka, M. Kolak, T. Kiviluoto, P. Arkkila, J. Siren, A. Hamsten et al., Genes involved in fatty acid partitioning and binding, lipolysis, monocyte/macrophage recruitment, and inflammation are overexpressed in the human fatty liver of insulin-resistant subjects, Diabetes 56 (2007), 2759-2765.

[40] T. Young, M. Palta, J. Dempsey, J. Skatrud, S. Weber and S. Badr, The occurrence of sleep-disordered breathing among middle-aged adults, $N$ Engl J Med 328 (1993), 1230-1235.

[41] L.J. Zhao, P. Xiao, Y.J. Liu, D.H. Xiong, H. Shen, R.R. Recker et al., A genome-wide linkage scan for quantitative trait loci underlying obesity related phenotypes in 434 Caucasian families, Hum Genet 121 (2007), 145-148. 


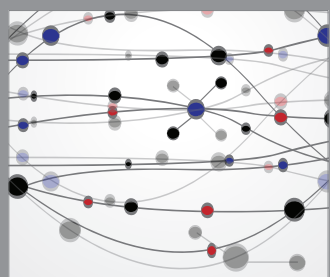

The Scientific World Journal
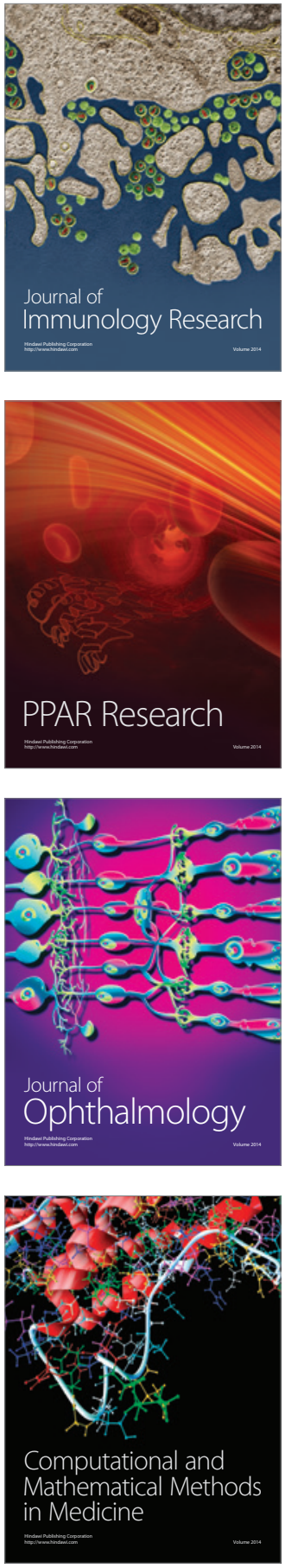

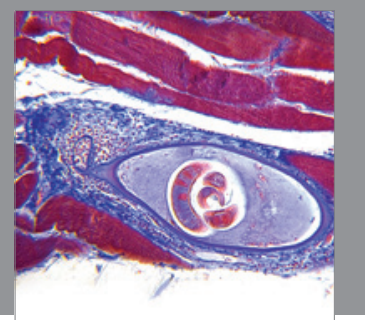

Gastroenterology

Research and Practice
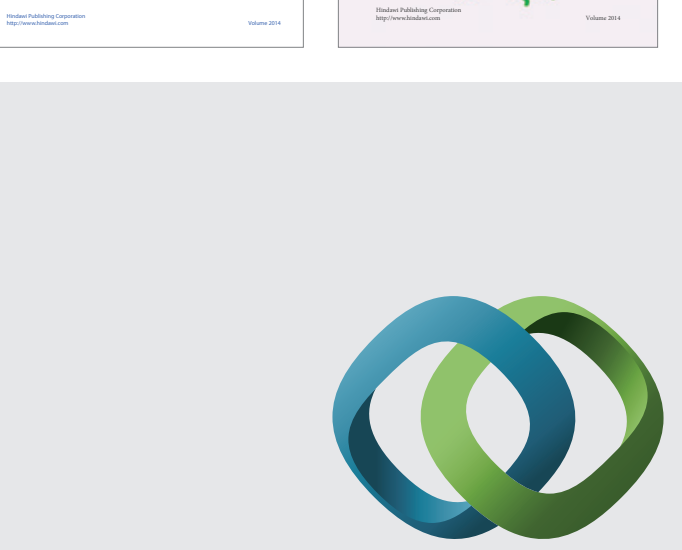

\section{Hindawi}

Submit your manuscripts at

http://www.hindawi.com
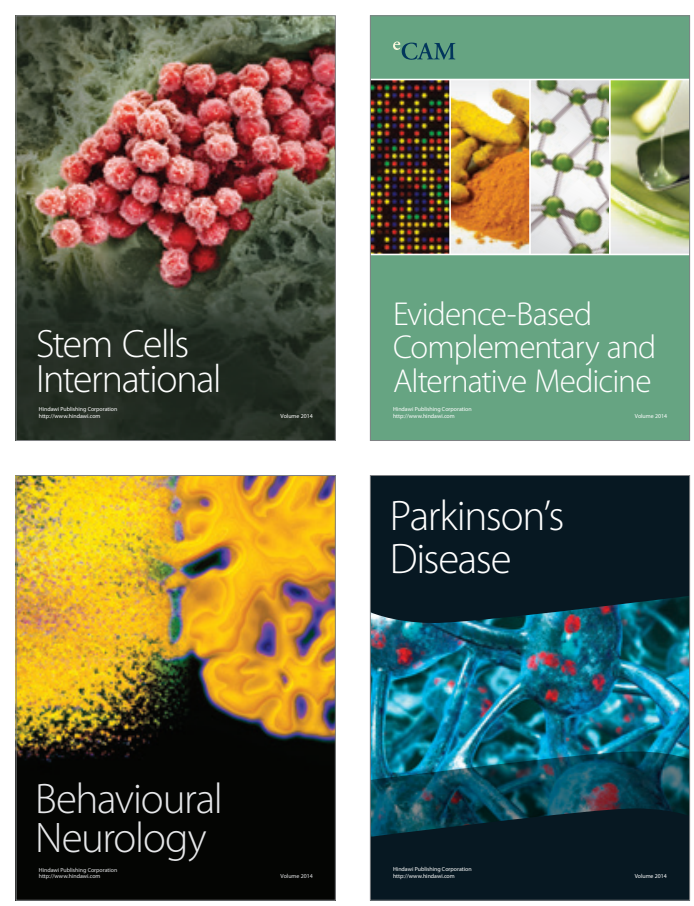

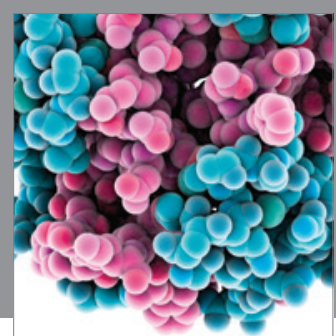

Journal of
Diabetes Research

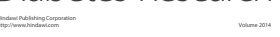

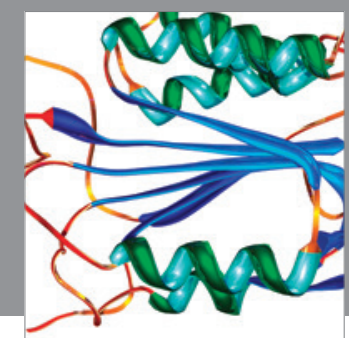

Disease Markers
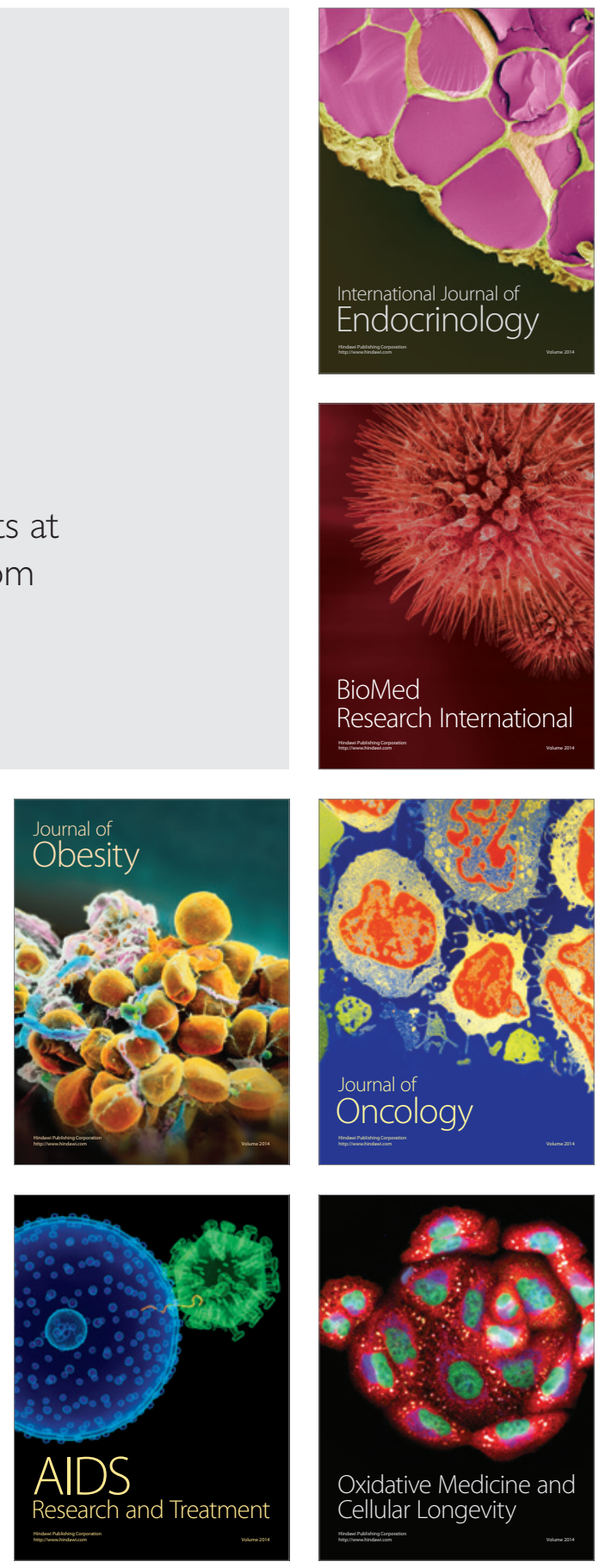